\title{
Clonidine decreases kynurenic acid production in rat brain cortex in vitro - a novel antihypertensive mechanism of action?
}

\author{
Izabela Zakrocka', Waldemar Turski', Tomasz Kocki' \\ ${ }^{1}$ Department of Experimental and Clinical Pharmacology, Medical University of Lublin, Poland
}

Zakrocka I, Turski W, Kocki T. Clonidine decreases kynurenic acid production in rat brain cortex in vitro - a novel antihypertensive mechanism of action? J Pre-Clin Clin Res. 2016; 10(1): 57-59. doi: 10.5604/18982395.1208190

\begin{abstract}
Introduction and objective. Clonidine, an antihypertensive agent, is known to activate presynaptic a2-adrenoreceptors and imidazoline receptors in the central nervous system. Clonidine may also have influence on glutamatergic neurotransmission. Kynurenic acid (KYNA) is an endogenous antagonist of excitatory amino acid receptors. Cerebral KYNA synthesis from its bioprecursor L-kynurenine is regulated by aminotransferases localized preferentially within astrocytes. KYNA was shown to display potent neuroprotective properties. Moreover, it was reported that KYNA could reduce blood pressure levels in animal model of hypertension. The aim of the study was to discover whether the central antihypertensive agent clonidine has an influence on kynurenic acid (KYNA) production in rat brain cortex in vitro.

Materials and method. Cortical slices and brain cortical homogenates were incubated for 2 hours in the presence of KYNA precursor - L-kynurenine and clonidine. KYNA was separated chromatographically and detected fluorometrically.

Results. Clonidine at the concentration of $0.001 \mathrm{mM}-0.1 \mathrm{mM}$ did not affect KYNA production in rat brain cortex in vitro. It decreased KYNA production in rat brain cortical slices at concentrations $0.5-5 \mathrm{mM}$. Clonidine at all tested concentrations influenced neither KAT I nor KAT II activity.

Conclusion. The study revealed that clonidine decreases KYNA production in rat brain cortex in vitro. The obtained results suggest that augmentation of glutamatergic transmission may play an important role in the antihypertensive action of clonidine.
\end{abstract}

Key words

kynurenic acid, clonidine, arterial hypertension, central nervous system, brain cortex

\section{INTRODUCTION}

Clonidine is a centrally- acting antihypertensive agent which activates both imidazoline receptors $\left(\mathrm{I}_{1}\right)$ and $\alpha_{2}$-adrenergic receptors in the central nervous system $[1,2]$. The exact mechanism by which clonidine decreases blood pressure is not fully understood.

It is known that clonidine may have an influence on glutamatergic neurotransmission [3]. Glutamate (GLU) is the main excitatory mediator leading to neuronal fibers activation in the RVLM (rostral ventrolateral medulla) [4]. It is well documented that both N-methyl-D-aspartate (NMDA) and a-amino-3-hydroxy-5-methyl-4-isoxazolepropionic acid (AMPA)/kainate receptors influence blood pressure level [5]. Furthermore, it was found that GLU administered intracerebrally leads to pressor cardiovascular responses [6]. Interestingly, NMDA or AMPA receptor antagonists were shown to abolish the decrease in blood pressure and heart rate evoked by intracerebroventricular administration of clonidine [7]. Similar effects were observed when clonidine was given intravenously $[8,9]$.

Kynurenic acid (KYNA) is the only known endogenous antagonist of GLU and a7-nicotinic receptors [10]. Cerebral synthesis of KYNA from its bioprecursor L-kynurenine is catalyzed by kynurenine aminotransferases (KAT) localized

Address for correspondence: Izabela Zakrocka, Collegium Pathologicum, Department of Experimental and Clinical Pharmacology, Jaczewskiego 8, 20-090 Lublin, Poland

E-mail: izabela.zakrocka@umlub.pl

Received: 30 November 2015; accepted: 28 January 2016 preferentially within astrocytes. Isoforms KAT I and KAT II are mainly responsible for the formation of KYNA in the brain. KYNA was shown to display potent neuroprotective properties and its impaired production was implicated in central nervous system diseases [11]. Additionally, it has been reported that KYNA could play a role in the regulation of blood pressure since a significant reduction of blood pressure has been achieved by KYNA administration to the RVLM in an animal model of hypertension [12]. However, KYNA did not change basal blood pressure levels in freely moving [13] or anesthetized normotensive animals after intrathecal [14] or intra-RVLM administration [12], but reversed cardiovascular stimulation caused by the RVLM activation.

\section{OBJECTIVES}

The aim of the study was to examine whether clonidine affects KYNA synthesis in rat brain cortex in vitro.

\section{MATERIALS AND METHOD}

Experiments were conducted on male Wistar rats (weight 150-200 g). Animals were kept under standard laboratory conditions at $20^{\circ} \mathrm{C}$ temperature, 12 -hours light-dark cycles, with food and water available ad libitum. Experiments were performed between 07:00-13:00. All utilized procedures were approved by the I Local Ethics Committee for Animal Experiments and are in agreement with Directive 
2010/63/EU on the protection of animals used for scientific purposes.

L-kynurenine (sulfate salt), clonidine hydrochloride and reagents used to prepare Krebs-Ringer buffer (sodium chloride, potassium chloride, magnesium sulfate, calcium chloride, sodium phosphate monobasic, sodium phosphate dibasic, glucose, distilled water), dialysate buffer (Trizma base, acetic acid, pyridoxal 5'-phosphate, 2-mercaptoethanol, distilled water) and incubation solutions to measure enzyme activity (Trizma base, acetic acid, pyruvate, pyridoxal 5 '-phosphate, glutamine, L-kynurenine, distilled water), were purchased from Sigma-Aldrich. Substances used to elute KYNA (hydrochloric acid, water, Dowex $50 \mathrm{~W}+$ ) and to perform high pressure liquid chromatography (water, acetonitrile, zinc acetate, sodium acetate) were obtained from J. T. Baker Chemicals and from Sigma-Aldrich.

To prepare fresh cortical slices, the rats were decapitated, their brains removed from the skulls and placed into ice cold Krebs-Ringer buffer, as described previously [15]. Dissected brain cortex was immediately cut with a McIlwain tissue slicer. Cortical slices $(1 \mathrm{~mm} \times 1 \mathrm{~mm})$ were placed into incubation wells (10 slices in each well) filled with oxygenated Krebs-Ringer buffer at pH 7.4. Each well contained $1 \mathrm{ml}$ of Krebs-Ringer buffer. Incubation was carried out for 2 hours at $37^{\circ} \mathrm{C}$ in the presence of $10 \mu \mathrm{M}$ of L-kynurenine and 7 different clonidine concentrations (0.001 $\mathrm{mM}$; $0.01 \mathrm{mM}$; $0.1 \mathrm{mM}$; $0.5 \mathrm{mM} ; 1 \mathrm{mM} ; 3 \mathrm{mM}$ or $5 \mathrm{mM})$. A minimum of 6 wells were used to examine each clonidine concentration. After incubation, the obtained supernatants were centrifuged and applied to ion exchange resin Dowex $50 \mathrm{~W}+$ column. Eluted KYNA was analyzed by HPLC and quantified fluorometrically (ThermoFisher Scientific HPLC system; ESA catecholamine $\mathrm{HR}-80,3 \mu \mathrm{m}, \mathrm{C}_{18}$ reverse-phase column). Experiments were conducted at least 3 times to achieve comparable results.

To assess KAT I and KAT II activity, rat brain cortex obtained after decapitation were homogenized in the dialysate buffer containing $5 \mathrm{mM}$ Tris-acetate buffer at $\mathrm{pH} 8.0,50 \mu \mathrm{M}$ pyridoxal 5'-phosphate and $10 \mathrm{mM}$ 2-mercaptoethanol. Prepared brain cortical homogenate was centrifuged, then the supernatant was dialyzed for 12 hours at $8^{\circ} \mathrm{C}$ with the use of cellulose membrane dialysis tubing in $4 \mathrm{l}$ of the dialysate buffer, prepared as described previously. Later, homogenate was incubated in the mixture containing the incubation solution (different for KAT I and KAT II), L - kynurenine and clonidine's solutions (7 tested concentrations). The reaction $\mathrm{pH}$ was 9.5 for KAT I activity and 7.0 for KAT II activity. At the end of sample preparation, L-glutamine was added to inhibit further KAT I activity. Three probes were used for each concentration of clonidine. After the incubation for 2 hours at $37^{\circ} \mathrm{C}$, the samples were placed into an ice cold bath, then centrifuged and analyzed the same as samples from the cortical slices. Each experiment was conducted a minimum of 3 times.

Data were presented as a percentage of control values. Mean and standard error of the mean (SEM) was calculated. Statistical analysis was performed using one way analysis of variance (ANOVA) with post-hoc Tuckey-Kramer test. Statistical significance was set at $\mathrm{P}<0.05$. All calculations were made with GraphPad InStat program, version 3.06.

\section{RESULTS}

Clonidine at the concentration of $0.001 \mathrm{mM}-0.1 \mathrm{mM}$ did not affect KYNA production in rat brain cortical slices in vitro. In higher concentrations of $0.5 \mathrm{mM} ; 1 \mathrm{mM} ; 3 \mathrm{mM}$ and $5 \mathrm{mM}$ it decreased KYNA production in rat brain cortical slices to $75 \%(\mathrm{P}<0.01), 80 \%(\mathrm{P}<0.05), 70 \%(\mathrm{P}<0.01)$ and $40 \%$ $(\mathrm{P}<0.001)$ of control, respectively (Fig. 1). Clonidine at the concentration of $0.001 \mathrm{mM}-5 \mathrm{mM}$ affected neither KAT I nor KAT II activity in homogenates of rat brain cortex (data not shown).

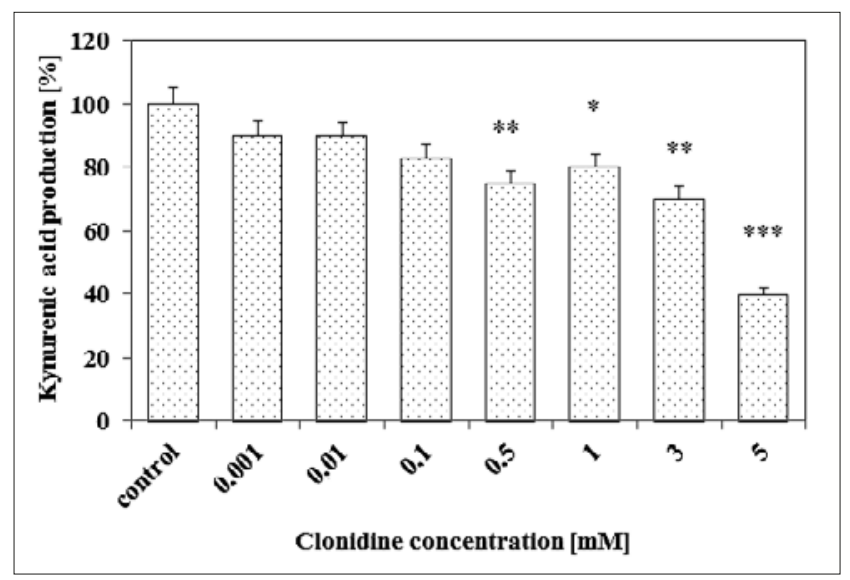

Figure 1. The influence of clonidine on KYNA production in rat brain cortex in vitro. Data are expressed as a percentage of control production, mean $\pm S E M, n=6$, ANOVA with post-hoc Tuckey-Kramer test, ${ }^{*} P<0.05,{ }^{* *} P<0.01,{ }^{* * *} P<0.001$ vs control

\section{DISCUSSION}

In the presented study it was found that clonidine reduced KYNA production in rat brain cortical slices. Since KYNA passes poorly through the blood-brain barrier [16], its brain activity is determined by its production in the central nervous system. Clonidine did not influence the activity of the 2 main isoforms of enzyme catalyzing KYNA production KAT I and KAT II, thus suggesting a non-enzymatic action of the drug.

The canonical mechanism of action of clonidine is an activation of imidazoline $\left(I_{1}\right)$ receptors and $\alpha_{2}$-adrenergic receptors [4]. It was also shown that clonidine may influence glutamatergic neurotransmission. Clonidine decreases GLU release in the spinal cord and brain structures $[17,18,19,20]$. However, a hypothetical decrease of GLU release induced by clonidine cannot explain the inhibition of KYNA production in cortical slices. On the contrary, an increase should be expected, since GLU dose-dependently reduces KYNA synthesis in the brain and spinal cord slices [21].

Interestingly, suggestions of a common binding site of $\mathrm{I}_{1} \mathrm{R}$ and NMDA or AMPA/kainate receptors have been presented. An electrophysiological study showed that 8 imidazolines, including clonidine, dose-dependently and non-competitively inhibited NMDA currents [22]. Furthermore, it was proposed that a binding site for imidazolines is located within the NMDA channel pore [23, 24].

There is also strong evidence of a functional interaction between GLU and imidazolines within the RVLM influencing cardiovascular regulation. It has been reported that intraRVLM injection of 6-cyano-7-nitroquinoxaline-2,3-dione (CNQX), a potent AMPA/kainate receptor antagonist, attenuated the reduction in blood pressure, heart rate, and 
renal sympathetic nerve activity elicited by intra-RVLM or intravenous clonidine [8]. Similarly, it was demonstrated that direct intra-RVLM injection of NMDA receptor antagonist dizocilpine significantly attenuated the decrease in blood pressure and heart rate induced by intracerebral clonidine, and antagonized the bradycardia and hypotension produced by intravenously administered clonidine [9]. Importantly, KYNA injected intracerebroventricularly was shown to reverse cardiovascular response to clonidine [7]. Thus, taking into account that KYNA is a broad spectrum GLU antagonist acting on both NMDA and AMPA/kainate receptors, it can be speculated that reduction of KYNA synthesis elicited by clonidine may result in amelioration of the antihypertensive action of the drug.

\section{CONCLUSIONS}

In conclusion, the obtained findings prompt the suggestion of a novel mechanism of action of clonidine, and probably other antihypertensive imidazolines as well.

\section{Acknowledgements}

This study was supported by a Grant for Young Scientists from Polish Ministry of Science and Higher Education in Warsaw, No. MNmb515/2013.

\section{REFERNCES}

1. Isaac L. Clonidine in the central nervous system: site and mechanism of hypotensive action. J Cardiovasc Pharmacol. 1980; 2: S5-19.

2. Kuz'min AI, Lodygin DN, Kalenikova EI, Bychkova EIu, Khokhlova ON, Murashev AN et al. Pharmacological analysis of the role of central alpha-2 adrenergic and imidazoline receptors in mechanism of the hypotensive effect of clonidine in rats. Eksp Klin Farmakol. 2000; 63: $24-8$.

3. Tingley FD 3rd, Arnerić SP. Evidence for clonidine presynaptically modulating amino acid release in the rostral ventral medulla: role in hypertension. Brain Res. 1990; 537: 175-81.

4. Reis DJ. Neurons and receptors in the rostroventrolateral medulla mediating the antihypertensive actions of drugs acting at imidazoline receptors. J Cardiovasc Pharmacol. 1996; 27: S11-18.

5. Sved AF, Ito S, Yajima Y. Role of excitatory amino acid inputs to the rostral ventrolateral medulla in cardiovascular regulation. Clin Exp Pharmacol Physiol. 2002; 29: 503-6.

6. Bergamaschi C, Campos RR, Schor N, Lopes OU. Role of the rostral ventrolateral medulla in maintenance of blood pressure in rats with Goldblatt hypertension. Hypertension. 1995; 26: 1117-20.

7. Wang LG, Zeng J, Yuan WJ, Su DF, Wang WZ. Comparative study of NMDA and AMPA/kainate receptors involved in cardiovascular inhibition produced by imidazoline-like drugs in anaesthetized rats. Exp Physiol. 2007; 92: 849-58.
8. Wang WZ, Wang LG, Gao L, Wang W. Contribution of AMPA/kainate receptors in the rostral ventrolateral medulla to the hypotensive and sympathoinhibitory effects of clonidine. Am J Physiol Regul Integr Comp Physiol. 2007; 293: R1232-8.

9. Wang WZ, Yuan WJ, Su DF. Blockade of N-methyl-D-aspartate receptors within the rostral ventrolateral medulla antagonizes clonidine-induced cardiovascular effects. Auton Neurosci. 2003; 109: 21-8.

10. Hilmas C, Pereira EF, Alkondon M, Rassoulpour A, Schwarcz R, Albuquerque EX. The brain metabolite kynurenic acid inhibits alpha7 nicotinic receptor activity and increases non-alpha7 nicotinic receptor expression: physiopathological implications. J Neurosci. 2001; 21: 7463-73.

11. Schwarcz R, Pellicciari R. Manipulation of brain kynurenines: glial targets, neuronal effects, and clinical opportunities. J Pharmacol Exp Ther. 2002; 303: 1-10.

12. Ito S, Komatsu K, Tsukamoto K, Sved AF. Excitatory amino acids in the rostral ventrolateral medulla support blood pressure in spontaneously hypertensive rats. Hypertension. 2000; 35: 413-7.

13. Araujo GC, Lopes OU, Campos RR. Importance of glycinergic and glutamatergic synapses within the rostral ventrolateral medulla for blood pressure regulation in conscious rats. Hypertension. 1999; 34 : 752-5.

14. Mills E, Minson J, Drolet G, Chalmers J. Effect of intrathecal amino acid receptor antagonists on basal blood pressure and pressor responses to brainstem stimulation in normotensive and hypertensive rats. J Cardiovasc Pharmacol. 1990; 15: 877-83.

15. Turski WA, Gramsbergen JB, Traitler H, Schwarcz R. Rat brain slices produce and liberate kynurenic acid upon exposure to L-kynurenine. J Neurochem. 1989; 52: 1629-36.

16. Fukui S, Schwarcz R, Rapoport SI, Takada Y, Smith QR. Blood-brain barrier transport of kynurenines: implications for brain synthesis and metabolism. J Neurochem. 1991; 56: 2007-17.

17. Kamisaki Y, Hamada T, Maeda K, Ishimura M, Itoh T. Presynaptic alpha 2 adrenoceptors inhibit glutamate release from rat spinal cord synaptosomes. J Neurochem. 1993; 60: 522-6.

18. Meana JJ, Herrera-Marschitz M, Goiny M. In vivo modulation of norepinephrine and glutamate release through imidazoline receptors in the rat central nervous system. Ann N Y Acad Sci. 1995; 763: 490-3.

19. Bickler PE, Hansen BM. Alpha 2-adrenergic agonists reduce glutamate release and glutamate receptor-mediated calcium changes in hippocampal slices during hypoxia. Neuropharmacology. 1996; 35: 679-87.

20. Shinomura T, Nakao S, Adachi T, Shingu K. Clonidine inhibits and phorbol acetate activates glutamate release from rat spinal synaptoneurosomes. Anesth Analg. 1999; 88: 1401-5.

21. Urbańska EM, Chmielewski M, Kocki T, Turski WA. Formation of endogenous glutamatergic receptors antagonist kynurenic aciddifferences between cortical and spinal cord slices. Brain Res. 2000; 878: 210-2.

22. Milhaud D, Fagni L, Bockaert J, Lafon-Cazal M. Imidazoline-induced neuroprotective effects result from blockade of NMDA receptor channels in neuronal cultures. Neuropharmacology. 2000; 39: 2244-54.

23. Olmos G, Ribera J, García-Sevilla JA. Imidazoli(di)ne compounds interact with the phencyclidine site of NMDA receptors in the rat brain. Eur J Pharmacol. 1996; 310: 273-6.

24. Olmos G, DeGregorio-Rocasolano N, Paz Regalado M, Gasull T, Assumpció Boronat M, Trullas $\mathrm{R}$ et al. Protection by imidazol(ine) drugs and agmatine of glutamate-induced neurotoxicity in cultured cerebellar granule cells through blockade of NMDA receptor. Br J Pharmacol. 1997; 127: 1317-26. 